\title{
ANALISIS PENGARUH BRAND NAME, SERVICE QUALITY, DAN PROMOTION TERHADAP KEPUTUSAN PEMBELIAN KONSUMEN PADA MINISO TUNJUNGAN PLAZA SURABAYA
}

\author{
Lidwina RA Sinaga \& Natasya Intan Pramanda \\ Fakultas Ekonomi dan Bisnis, Universitas Airlangga \\ E-mail: lidwinasinaga@gmail.com \& intanpramanda@gmail.com
}

\begin{abstract}
ABSTRAK
Konsumen kelas menengah membutuhkan produk dengan kualitas baik, harga kompetitif, dan gaya hidup. Salah satu faktor yang mempengaruhi perilaku konsumen dalam pembelian adalah gaya hidup. Perusahaan harus memahami proses keputusan pembelian konsumen, terutama dalam hal nama merek, kualitas layanan dan promosi. Penelitian ini terbatas pada outlet Miniso di Tunjungan Plaza Surabaya. Responden penelitian terbatas pada pengunjung Miniso Tunjungan Plaza Suraaya dalam rentang usia 17-35 tahun. Jenis penelitian ini adalah penelitian deskriptif kuantitatif dan instrumen yang digunakan berupa kuesioner. Teknik analisis data menggunakan analisis data deskriptif kuantitatif. Validitas data diperoleh melalui validitas dan reliabilitas. Berdasarkan analisis pengaruh nama merek, kualitas layanan dan promosi keputusan pembelian pelanggan di Miniso Tunjungan Plaza Surabaya dari bulan April hingga Mei 2018 hasilnya adalah Nama Merek (X1) memiliki pengaruh positif terhadap Keputusan Pembelian Pelanggan (Y). Kualitas Layanan (X2) memiliki pengaruh positif pada Keputusan Pembelian Pelanggan (Y). Dengan demikian, peningkatan atau penurunan dalam keputusan pembelian pelanggan dapat dijelaskan secara langsung oleh kualitas layanan. Promosi (X3) memiliki pengaruh positif terhadap Keputusan Pembelian Pelanggan (Y).
\end{abstract}

Kata kunci: keputusan pembelian, merek, kualitas layanan, promosi, Miniso, SmartPLS

\begin{abstract}
Middle-class consumers need products of good quality, competitive prices and lifestyle. One of the factors that influence consumer behavior in purchasing is lifestyle. Companies must understand the consumer purchase decision process especially in terms of brand name, service quality and promotion. This research is limited to Miniso outlet in Tunjungan Plaza Surabaya. Research respondents are limited to visitors of Miniso Tunjungan Plaza Suraaya in the 17-35 year age range. The type of this research is quantitative descriptive research and instrument used in the form of questionnaire. Data analysis technique used quantitative descriptive data analysis. The validity of data is obtained through validity and reliability. Based on the analysis of the influence of brand name, service quality and promotion of customer purchasing decisions at Miniso Tunjungan Plaza Surabaya from April to May 2018 the result is Brand Name (XI) has a positive influence on Customer Purchase Decision (Y). Service Quality (X2) has a positive influence on Customer Purchase Decision (Y). Thus, the increase or decrease in customer purchasing decisions can be explained directly by service quality. Promotion (X3) has a positive influence on Customer Purchase Decision (Y).
\end{abstract}

Keywords: purchasing decision, brand, service quality, promotion, Miniso, SmartPLS 


\section{Lidwina RA Sinaga \\ Natasya Intan Pramanda}

\section{PENDAHULUAN}

Faktor pertumbuhan ekonomi di era globalisasi yang terjadi sekarang ini menyebabkan kebutuhan manusia yang semakin banyak dan beragam, sehingga berpengaruh terhadap perkembangan pasar di Indonesia. Hal tersebut juga didorong dengan terus meningkatnya jumlah penduduk di Indonesia. Tingkat konsumsi dan daya beli masyarakat yang semakin tinggi, bertumbuh sesuai dengan pertumbuhan ekonomi.

Industri bisnis gaya hidup dalam beberapa tahun ke depan akan terus berkembang pesat karena dipengaruhi oleh faktor kebutuhan masyarakat dan meningkatnya pertumbuhan kelas menengah di Indonesia. Hal ini menjadikan peluang sekaligus tantangan dalam dunia bisnis, terutama dalam dunia bisnis ritel di Indonesia. Semakin banyaknya bisnis ritel yang berkembang menjadikan konsumen semakin selektif dalam memilih atau memutuskan tempat untuk memenuhi kebutuhan.

Ritel perlengkapan rumah tangga sudah mulai banyak di Indonesia. Salah satunya adalah Miniso yang di Indonesia dikelola oleh PT Miniso Lifestyle Indonesia. Miniso menjadikan konsumen kelas menengah sebagai segmen pasarnya. Konsumen kelas menengah memerlukan produk dengan kualitas baik, harga yang kompetitif dan juga menjual gaya hidup. Gaya hidup berpengaruh terhadap perilaku konsumen dalam melakukan proses keputusan pembelian, salah satunya terhadap dalam keputusan pembelian peralatan rumah tangga seperti dalam penelitian ini. Perusahaan harus memahami proses keputusan pembelian konsumen pada tiap-tiap tahap dan pengaruh apa saja yang bekerja dalam tahap-tahap tersebut khususnya dalam hal brand name, service quality dan promotion.

Sehingga dari latar belakang diatas, dapat dirumuskan permasalahan yang akan dibahas pada penelitian ini yaitu (1) Apakah Brand Name berpengaruh positif terhadap keputusan pembelian pelanggan pada Miniso Tunjungan Plaza Surabaya? (2) Apakah Service Quality berpengaruh positif terhadap keputusan pembelian pelanggan pada Miniso Tunjungan Plaza Surabaya? (3) Apakah Promotion berpengaruh positif terhadap keputusan pembelian pelanggan pada Miniso Tunjungan Plaza Surabaya?

Batasan masalah pada penelitian ini yaitu responden dibatasi kepada konsumen yang pernah membeli produk Miniso di Tunjungan Plaza Surabaya dan kuesioner disebar pada periode Maret sampai April 2018. 


\section{TINJAUAN PUSTAKA}

\section{Brand}

Menurut Kotler \& Armstrong (2014: 255), brand adalah suatu nama, istilah, simbol, desain, atau kombinasi dari salah satu bagian tersebut yang mengidentifikasi produk atau layanan dari satu penjual atau kelompok penjual dan membedakannya dari pesaing. Brand name membantu konsumen dalam melakukan identifikasi produk yang dapat memberikan benefit kepada mereka(Kotler \& Armstrong, 2014: 255).

\section{Service Quality}

Menurut Kotler dan Armstrong (2014: 249), jasa adalah aktivitas, benefit, maupun kepuasan yang ditawarkan untuk dijual dimana bentuknya tidak berwujud dan tidak menghasilkan kepemilikan apapun (Kotler \& Armstrong, 2014: 249). Menurut Tjiptono \& Chandra (201 1: 180), kualitas layanan merupakan suatu ukuran seberapa baik tingkat pelayanan yang diberikan dapat diberikan oleh perusahaan dalam memenuhi kebutuhan dan keinginan pelanggan sesuai dengan ekspektasi pelanggan (Tjiptono \& Chandra, 2011: 180).

\section{Promotion}

Promosi menurut Kotler \& Armstrong (2014: 77) adalah bagian dari marketing mix yang merupakan aktivitas komunikasi yang dilakukan oleh perusahaan untuk mempengaruhi pelanggan agar membeli produk yang dijual oleh perusahaan. Promosi mencakup iklan, penjualan langsung, promosi penjualan, hubungan dengan pelanggan (Kotler \& Armstrong, 2014: 477). Menurut Belch \& Belch (2015: 16), promosi didefinisikan sebagai kordinasi dari semua upaya yang dilakukan oleh penjual dalam menyiapkan saluran informasi dan persuasi untuk menjual barang dan jasa atau mempromosikan sebuah ide (Belch \& Belch, 2015: 16).

\section{Keputusan Pembelian}

Schiffman \& Kanuk (2010: 23) mengatakan bahwa perilaku konsumen didefinisikan sebagai perilaku konsumen yang ditampilkan dalam hal mencari, membeli, menggunakan, mengevaluasi dan menghabiskan barang dan jasa yang diharapkan akan memuaskan kebutuhan mereka (Schiffman \& Kanuk, 2010: 23). Pada perilaku konsumen terdapat perilaku membeli konsumen yang dijelaskan oleh Kotler \& Armstrong (2014: 158), bahwa perilaku membeli konsumen adalah perilaku membeli dari konsumen akhir baik individu, kelompok maupun organisasi yang membeli barang dan jasa untuk keperluan konsumsi atau penggunaan personal (Kotler \& Armstrong, 2014: 148). Kotler \& Armstrong (2014: 159174) juga menambahkan bahwa terdapat beberapa faktor yang mempengaruhi perilaku pembelian konsumen seperti pada Gambar 1, yaitu: 
Lidwina RA Sinaga

Natasya Intan Pramanda

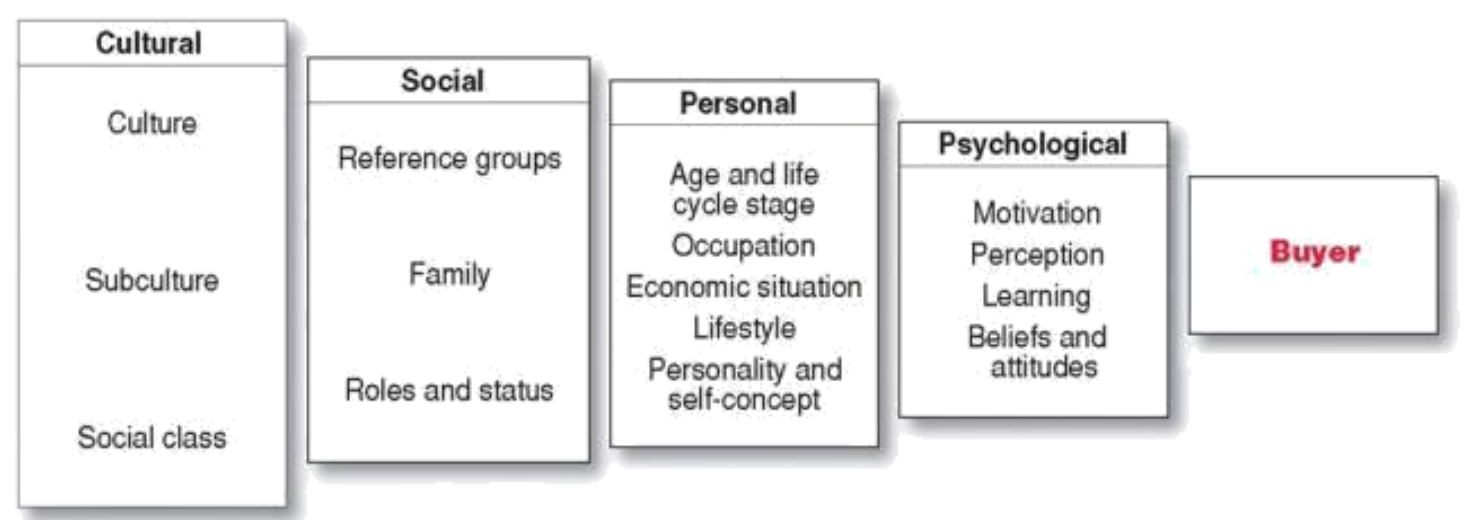

Gambar 1. Faktor yang Mempengaruhi Perilaku Konsumen

Sumber: Kotler \& Armstrong, 2014

\section{METODE}

Strategi penelitian yang digunakan dalam penelitian ini adalah dengan melakukan survei. Unit analisis yang digunakan dalam penelitian ini adalah individual atau pelanggan yang dalam hal ini adalah konsumen yang mengunjungi dan membeli produk Miniso Tunjungan Plaza Surabaya. Waktu yang digunakan adalah cross sectional/one-shot studies.

Pada penelitian ini pertanyaan yang mencakup karakteristik responden menggunakan skala pengukuran nominal dimana setiap indikator kuesioner dikelompokkan menjadi suatu kategori yang akan diteliti. Pernyataan yang bertujuan mengukur dependent variable dan independent variable akan diukur menggunakan skala pengukuran interval yang berupa Skala Likert dikarenakan indikator kuesioner diuji untuk mengelompokkan dan mengukur besarnya perbedaan preferensi di antara individu atas pernyataan yang diberikan dalam kuesioner.

Peneliti menggunakan metode analisis jenis data kuantitatif. Sekaran \& Bougie (2013: 274) berpendapat bahwa kuantitatif adalah data yang didapat dari sampel suatu populasi yang dianalisis untuk diuji hipotesisnya. Populasi yang digunakan adalah konsumen yang mengunjungi produk Miniso Tunjungan Plaza Surabaya. sampel yang digunakan adalah beberapa konsumen yang sudah pernah membeli produk di Miniso Tunjungan Plaza Surabaya. Analisis data pada penelitian ini dilakukan dengan menggunakan bantuan komputer yaitu dengan program SmartPLS 3.0 menggunakan metode Structural Equation Modeling - Partial Least Square (SEM - PLS) (Sekaran \& Bougie, 2013: 274). 
Tabel 1. Operasional Variabel Penelitian

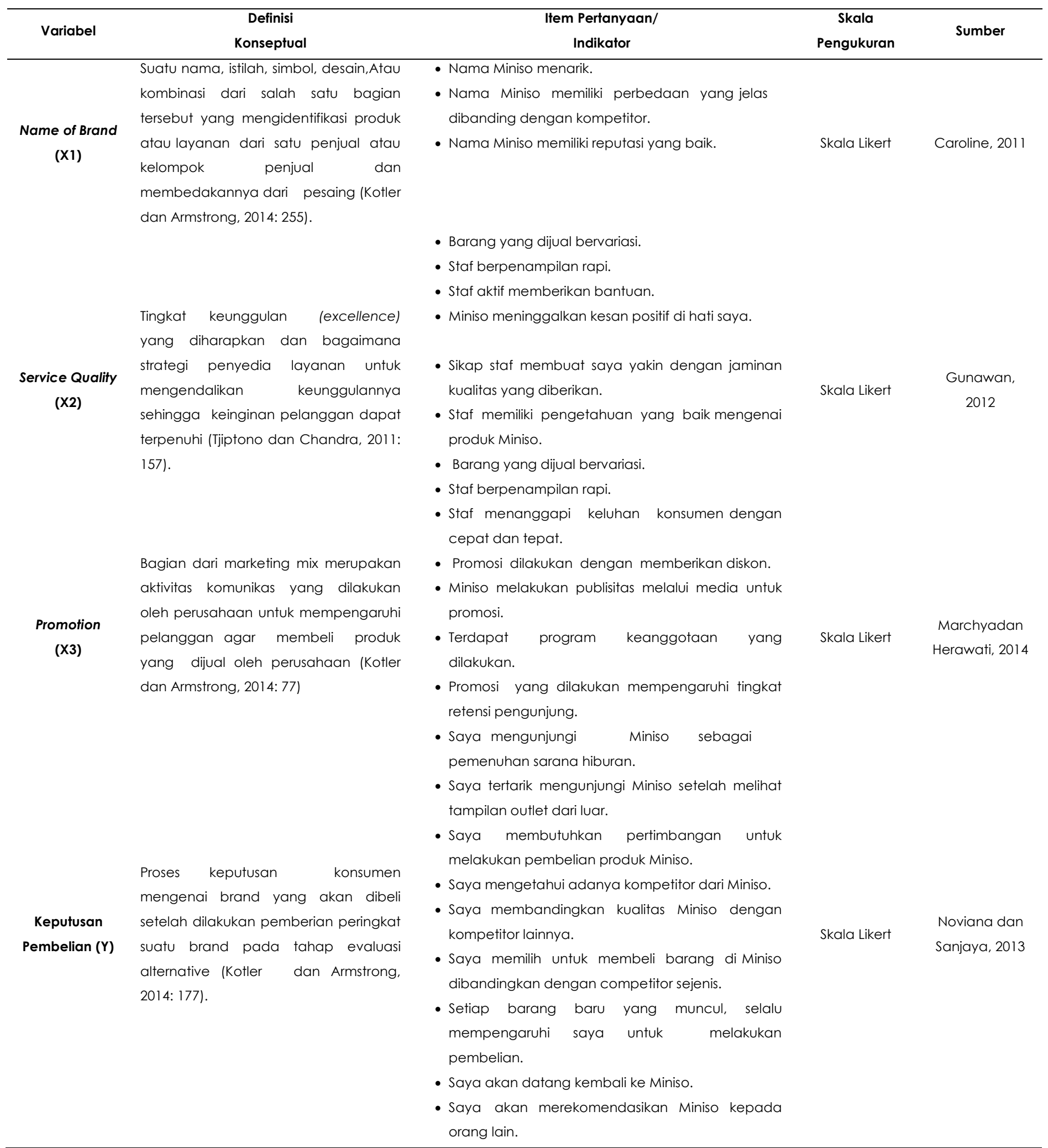




\section{Lidwina RA Sinaga}

\section{Natasya Intan Pramanda}

\section{GAMBARAN UMUM SUBYEK DAN OBYEK PENELITIAN}

\section{Profil Perusahaan}

Miniso adalah sebuah merek desainer yang berbasis di Jepang, didirikan oleh desainer Jepang Mr. Miyake Junya bersama dengan seorang pengusaha muda dari Cina yang bernama Mr. Ye Guofu di Tokyo, Jepang. Miniso adalah promotor global "produk konsumen cerdas". Miniso berpegang pada filosofi hidup "kesederhanaan, sifat dan kualitas yang baik" dan proposisi merek "kembali ke alam". Miniso mendapatkan popularitas di kalangan konsumen dengan cara memperbarui produk setiap tujuh hari, membuat harga pada tingkat rendah, dan menargetkan pada rantai produk konsumen yang cerdas. Miniso berhasil menetapkan tren konsumsi cerdas pribadi di pasar perbatasan konsumsi rumah tangga dengan cara ini. Miniso memasuki pasar Cina pada September 2013, untuk secara komprehensif masuk ke pasar produk konsumen cerdas di China.

Miniso aktif mengeksplorasi pasar internasional dan telah membuka lebih dari 2600 toko dalam waktu kurang dari empat tahun, dengan perputaran bisnis berdiri di USD 750 juta pada tahun 2015 dan hampir USD 1,5 miliar pada tahun 2016 sejak Miniso didirikan di Jepang pada tahun 2013. Pada tahun 2017, volume penjualan Miniso mencapai USD 1,8 miliar. Saat ini, Miniso telah mencapai kesepakatan kerjasama strategis dengan lebih dari 60 negara dan wilayah termasuk Amerika Serikat, Kanada, Rusia, Singapura, Uni Emirat Arab, Korea, Malaysia, Hong Kong (Cina) dan Makau (Cina), dengan rata-rata tingkat pertumbuhan bulanan 80 - 100 toko. Miniso menganjurkan filosofi hidup berkualitas dan slogan mereka adalah "menghormati konsumen", mendedikasikan diri untuk menyediakan pelanggan dengan "kualitas tinggi, harga kompetitif dan kreativitas".

\section{Profil Responden}

Pada penelitian ini, profil responden dibedakan berdasarkan kriteria responden pembeli produk di Miniso Tunjungan Plaza Surabaya berdasarkan jenis kelamin, usia, pendidikan terakhir, jenis pekerjaan, tingkat pendapatan, perolehan sumber informasi oleh responden. Penelitian dilakukan kepada 114 responden yang bersedia mengisi kuesioner yang diberikan oleh peneliti. Sebesar $68,4 \%$ responden memiliki jenis kelamin perempuan, sedangkan $31,6 \%$ responden berjenis kelamin laki-laki dari total responden dalam penelitian ini sejumlah 114 responden. Prosentase $67,5 \%$ mewakili 77 responden berusia 17 - 25 tahun, $23,7 \%$ mewakili 27 responden berusia 26 - 34 tahun, $7.9 \%$ mewakili 9 responden berusia lebih dari 34 tahun, dan $0.9 \%$ mewakili 1 dari 114 responden berusia kurang dari 17 tahun. Persebaran kuesioner kepada pengunjung Miniso Tunjungan Plaza Surabaya didominasi oleh pengunjung dengan usia 17 sampai dengan 25 tahun. 
Berdasarkan jenis pekerjaan, diketahui sebanyak $52.6 \%$ atau 60 responden merupakan karyawan swasta, 27.2\% atau 31 responden merupakan pelajar/mahasiswa, $12.3 \%$ atau 14 responden merupakan wiraswasta, dan sisanya berprofesi sebagai guru, calon legislatif, ibu rumah tangga, dan pegawai BUMN. Berdasarkan tingkat pendapatan, diketahui bahwa prosentase $43.2 \%$ atau 48 responden berpenghasilan $\operatorname{Rp} 2.000 .000$,- sampai $\operatorname{Rp~4.999.999,-;~}$ $22.5 \%$ atau 25 responden berpenghasilan Rp 5.000.000,- sampai Rp 7.999.999,-; $21.6 \%$ atau 24 responden berpenghasilan kurang dari Rp 2.000.000,-; dan $12.6 \%$ atau 14 responden berpenghasilan lebih dari Rp 8.000.000,- dari total 114 responden. Berdasarkan sumber informasi, diketahui dari total keseluruhan 114 responden bahwa persentase $54.4 \%$ atau 62 responden mengetahui Miniso saat berjalan-jalan di Tunjungan Plaza Surabaya secara langsung, 29.8\% atau 34 responden mengetahui dari teman/keluarga, $14.9 \%$ atau 17 responden mengetahui dari internet dan sosial media, dan tidak ada responden yang mengetahui Miniso dari iklan dan surat kabar.

\section{HASIL PENELITIAN DAN PEMBAHASAN}

Evaluasi model pengukuran yang digunakan dalam penelitian ini adalah model pengukuran reflektif yang terdiri dari pengukuran Loading Factor, Composite Reliability, Average Variance Extracted (AVE), Cronbanch's Alpha, Discriminant Validity dan Cross Loading. Model path yang menggambarkan alur penelitian ini juga terdapat dalam model pengukuran (Gambar 2).

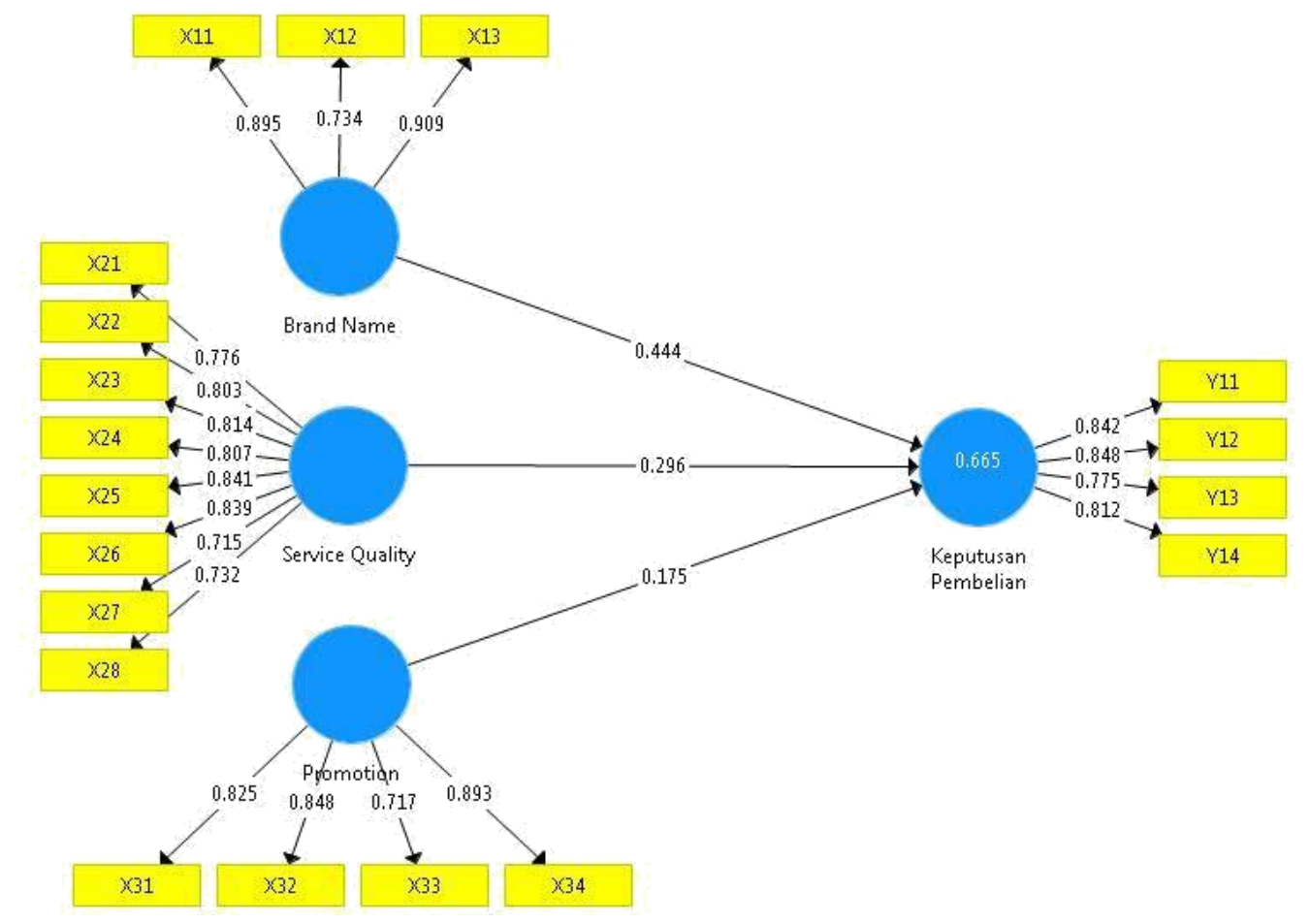

Gambar 2. Model Path

Sumber: Hasil Olah Data SmartPLS, 2018 


\section{Lidwina RA Sinaga}

\section{Natasya Intan Pramanda}

\section{Loading Factor}

Model pengukuran yang dilakukan dengan melihat convergent validity atau besar loading factor untuk masing-masing variabel. Nilai loading factor yang tinggi atau di atas 0.70 menandakan hubungan antara indikator dengan variabel. Pada Tabel 2 menunjukkan hasil pengolahan data kuesioner yang dikumpulkan sehingga diketahui loading factor untuk masing- masing indikator (Tabel 2).

\section{Tabel 2. Loading Factor Results}

\begin{tabular}{|c|c|c|c|c|}
\hline & Brand Name & $\begin{array}{l}\text { Service } \\
\text { Quality }\end{array}$ & Promotion & $\begin{array}{l}\text { Keputusan } \\
\text { Pembelian }\end{array}$ \\
\hline $\mathrm{X} 11$ & 0,895 & & & \\
\hline$\times 12$ & 0,734 & & & \\
\hline$x 13$ & 0,909 & & & \\
\hline X21 & & 0,776 & & \\
\hline$x 22$ & & 0,803 & & \\
\hline$x 23$ & & 0,814 & & \\
\hline X24 & & 0,807 & & \\
\hline$x 25$ & & 0,841 & & \\
\hline$x 26$ & & 0,839 & & \\
\hline$x 27$ & & 0,715 & & \\
\hline$x 28$ & & 0,732 & & \\
\hline x31 & & & 0,825 & \\
\hline x32 & & & 0,848 & \\
\hline x33 & & & 0,717 & \\
\hline X34 & & & 0,893 & \\
\hline Y11 & & & & 0,842 \\
\hline Y12 & & & & 0,848 \\
\hline Y13 & & & & 0,775 \\
\hline Y14 & & & & 0,812 \\
\hline
\end{tabular}

Sumber: Hasil Olah Data SmartPLS, 2018

\section{Composite Reliability}

Composite Reliability melakukan pengukuran konsistensi tingkat reliabilitas suatu variabel. Semakin tinggi nilai Composite Reliability menandakan bahwa variabel tersebut semakin tinggi tingkat reliabilitasnya. Nilai diantara 0.60 sampai dengan 0.70 dianggap dapat diterima dalam penelitian, sedangkan nilai antara 0.70 sampai dengan 0.95 dianggap memuaskan (Hair et al., 2014, 101-102). Nilai lebih besar dari 0.95 dianggap bermasalah karena menunjukkan indikator item yang berlebihan. Dari hasil olah data Composite Reliability setiap variabel menunjukkan nilai di atas 0.60 yang menandakan setiap variabel 
dalam penelitian ini sudah reliable dengan syarat pengukuran Composite Reliability (Tabel 3).

Tabel 3. Composite Reliability Results

\begin{tabular}{lc}
\hline \multicolumn{1}{c}{ Variabel } & Composite Reliability \\
\hline Brand Name & 0,886 \\
Service Quality & 0,931 \\
Promotion & 0,893 \\
Keputusan Pembelian & 0,891 \\
\hline \multicolumn{2}{c}{ Sumber: Hasil Olah Data SmartPLS, 2018 }
\end{tabular}

\section{Average Variance Extracted (AVE)}

Reliabilitas dari setiap variabel dapat dilakukan pengukuran dengan Average Variance Extracted ( $A V E$ ) dengan ketentuan nilai AVE lebih besar dari 0.50. Berdasarkan hasil olah data Average Variance Extracted (AVE) setiap variabel memiliki nilai di atas 0.50 sehingga setiap variabel dapat dinyatakan reliable (Tabel 4).

Tabel 4. Average Variance Extracted (AVE)

\begin{tabular}{lc}
\hline \multicolumn{1}{c}{ Variabel } & $\begin{array}{c}\text { Average Variance } \\
\text { Extracted (AVE) }\end{array}$ \\
\hline Brand Name & 0,722 \\
Service Quality & 0,672 \\
Promotion & 0,678 \\
Keputusan Pembelian & 0,627 \\
\hline
\end{tabular}

Sumber: Hasil Olah Data SmartPLS, 2018

\section{Cronbach's Alpha}

Model pengukuran yang menggunakan standard Cronbanch's Alpha mengukur nilai dari setiap variabel dan akan dinyatakan reliable apabila nilainya melebihi 0.60 . Tabel 5 menampilkan nilai hasil pengukuran Cronbanch's Alpha. Berdasarkan hasil olah data Cronbanch's Alpha maka setiap variabel dalam penelitian ini telah memenuhi syarat dengan nilai di atas 0.60 untuk dinyatakan reliable (Tabel 5).

\section{Tabel 5. Cronbach's Alpha}

\begin{tabular}{lc}
\hline \multicolumn{1}{c}{ Variabel } & Cronbach's Alpha \\
\hline Brand Name & 0,808 \\
Service Quality & 0,915 \\
Promotion & 0,843 \\
Keputusan Pembelian & 0,837 \\
\hline
\end{tabular}

Sumber: Hasil Olah Data SmartPLS, 2018 
Lidwina RA Sinaga

\section{Natasya Intan Pramanda}

\section{Discriminant Validity}

Model pengukuran discriminant validity merupakan metode pengukuran yang melakukan perhitungan akar kuadrat dari nilai Average Variance Extracted (AVE) dengan membandingkan nilai korelasi antar variabel dengan variabel lainnya (Tabel 6).

\section{Tabel 6. Discriminant Validity Results}

\begin{tabular}{lcccc}
\hline \multicolumn{1}{c}{ Variabel } & $\begin{array}{c}\text { Brand } \\
\text { Name }\end{array}$ & $\begin{array}{c}\text { Service } \\
\text { Quality }\end{array}$ & Promotion & $\begin{array}{c}\text { Keputusan } \\
\text { Pembeilian }\end{array}$ \\
\hline Brand Name & 0.850 & & & \\
Service Quality & 0.733 & 0.792 & 0.573 & 0.722 \\
Promotion & 0.624 & & 0.823 & 0.622 \\
Keputusan Pembelian & 0.770 & & & 0.820 \\
\hline
\end{tabular}

Sumber: Hasil Olah Data SmartPLS, 2018

\section{Cross Loading}

Model pengukuran cross loading merupakan metode pengukuran yang setiap nilai indikator atas setiap variabelnya memiliki nilai yang lebih tinggi dibandingkan dengan indikator dari variabel lain (Tabel 7).

Tabel 7. Cross Loading Results

\begin{tabular}{llccc}
\hline & Brand Name & $\begin{array}{c}\text { Service } \\
\text { Quality }\end{array}$ & Promotion & $\begin{array}{c}\text { Keputusan } \\
\text { Pembelian }\end{array}$ \\
\hline X11 & 0,895 & 0,736 & 0,550 & 0,755 \\
X12 & 0,734 & 0,460 & 0,534 & 0,451 \\
X13 & 0,909 & 0,721 & 0,528 & 0,622 \\
X21 & 0,677 & 0,728 & 0,447 & 0,776 \\
X22 & 0,607 & 0,592 & 0,502 & 0,803 \\
X23 & 0,490 & 0,463 & 0,454 & 0,814 \\
X24 & 0,553 & 0,497 & 0,479 & 0,807 \\
X25 & 0.534 & 0.508 & 0.415 & 0.841 \\
X26 & 0.614 & 0.653 & 0.430 & 0.839 \\
X27 & 0.551 & 0.470 & 0.409 & 0.715 \\
X28 & 0.555 & 0.550 & 0.489 & 0.732 \\
X31 & 0.464 & 0.448 & 0.825 & 0.472 \\
X32 & 0.563 & 0.583 & 0.848 & 0.495 \\
X33 & 0.421 & 0.306 & 0.717 & 0.279 \\
X34 & 0.575 & 0.618 & 0.893 & 0.568 \\
Y11 & 0.595 & 0.842 & 0.511 & 0.562 \\
Y12 & 0.662 & 0.848 & 0.491 & 0.651 \\
Y13 & 0.558 & 0.775 & 0.575 & 0.527 \\
Y14 & 0.698 & 0.812 & 0.470 & 0.617 \\
\hline
\end{tabular}

Sumber: Hasil Olah Data SmartPLS, 2018 


\section{Evaluasi Model Struktural}

Evaluasi model strukural yang digunakan dalam penelitian ini penilaian menggunakan uji koefisien determinasi (R-Square) untuk variabel dependen dan uji F-Square untuk mengetahui seberapa besar pengaruh variabel prediktor mempengaruhi variabel dependen.

\section{R-Square}

Model struktural dievaluasi dengan menggunakan R-Square untuk variabel dependen. Penilaian untuk R-Square dikategorikan sebagai pengaruh variabel independen terhadap variabel dependen dengan ketentuan sebagai berikut: $0.19=$ lemah, $0.33=$ moderat dan 0.67 = baik. Keputusan pembelian pelanggan yang merupakan variabel dependen memiliki nilai $R$-Square sebesar $66.5 \%$ yang berarti variabel tersebut dipengaruhi secara moderat oleh variabel independen yang terdiri dari brand name, service quality dan promotion. Sejumlah $33.5 \%$ variabel dependen dipengaruhi oleh variabel independen lain di luar penelitian ini (Tabel 8).

\section{Tabel 8. R-Square Results}

\begin{tabular}{cc}
\hline Variabel & R-Square \\
\hline Keputusan Pembelian & 0.665 \\
\hline \multicolumn{2}{c}{ Sumber: Hasil Olah Data SmartPLS, 2018}
\end{tabular}

\section{F-Square}

Evaluasi model struktural yang digunakan untuk menentukan kekuatan pengaruh dari variabel prediktor terhadap variabel dependen pada tingkat struktural dengan ketentuan nilai F-Square adalah sebagai berikut: $0.02=$ lemah, $0.15=$ medium dan 0.35 = besar. Berdasarkan hasil olah data F-Square maka dapat diketahui bahwa untuk variabel brand name dengan nilai 0.235 termasuk memiliki pengaruh medium pada tingkat struktural. Hal ini menandakan apabila variabel brand name dihilangkan dari model penelitian maka variabel tersebut memiliki pengaruh medium yang memiliki dampak cukup substatif terhadap variabel keputusan pembelian. Variabel promotion dengan nilai 0.053 termasuk memiliki pengaruh pada lemah pada tingkat struktural yang menandakan apabila variabel dihilangkan dari model penelitian maka variabel tersebut memiliki pengaruh yang tidak besar terhadap variabel keputusan pembelian. Variabel service quality memiliki pengaruh pada tingkat struktural menengah antara lemah dan sedang dengan nilai 0.115 yang menandakan apabila variabel dihilangkan dari model penelitian maka variabel tersebut memiliki dampak cukup substatif terhadap variabel keputusan pembelian (Tabel 9). 
Lidwina RA Sinaga

Natasya Intan Pramanda

Tabel 9. F-Square Results

\begin{tabular}{lc}
\hline \multicolumn{1}{c}{ Variabel } & Keputusan Pembelian \\
\hline Brand Name & 0,235 \\
Service Quality & 0,115 \\
Promotion & 0,053 \\
\hline
\end{tabular}

Sumber: Hasil Olah Data SmartPLS, 2018

\section{Path Coefficients}

Model struktural dilakukan evaluasi untuk menjelaskan besar pengaruh antara variabel dengan membandingkan hasil nilai uji T-statistik. Nilai T-Statistik dibandingkan dengan nilai TTabel yang akan signifikan jika lebih besar dari T-Tabel. Berdasarkan hasil pengujian hipotesis, Brand Name memiliki pengaruh positif terhadap Keputusan Pembelian pelanggan. Hal ini membuktikan bahwa keputusan pembelian yang ditentukan oleh pelanggan dipengaruhi oleh merek suatu produk. Konsumen akan memperhatikan merek yang dapat memberikan solusi atas permasalahan yang dialami setiap orang dan dalam hal ini adalah kebutuhan konsumen dalam membeli peralatan sehari-hari. Semakin suatu brand dikenal secara luas, mudah diingat oleh masyarakat, memiliki daya tarik dan memiliki perbedaan dengan kompetitor lainnya akan membuat pelanggan memilih brand tersebut. Selain itu reputasi dan informasi yang jelas dari suatu brand juga akan mempengaruhi pelanggan dalam memutuskan untuk membeli produk maupun jasa yang ditawarkan oleh perusahaan. Variabel brand name memiliki nilai uji F-Square terbesar diantara variabel yang diuji dalam penelitian ini yang menandakan bahwa terdapat pengaruh medium antara brand name terhadap keputusan pembelian pelanggan (Tabel 10).

Tabel 10. Hasil Path Ceofficients

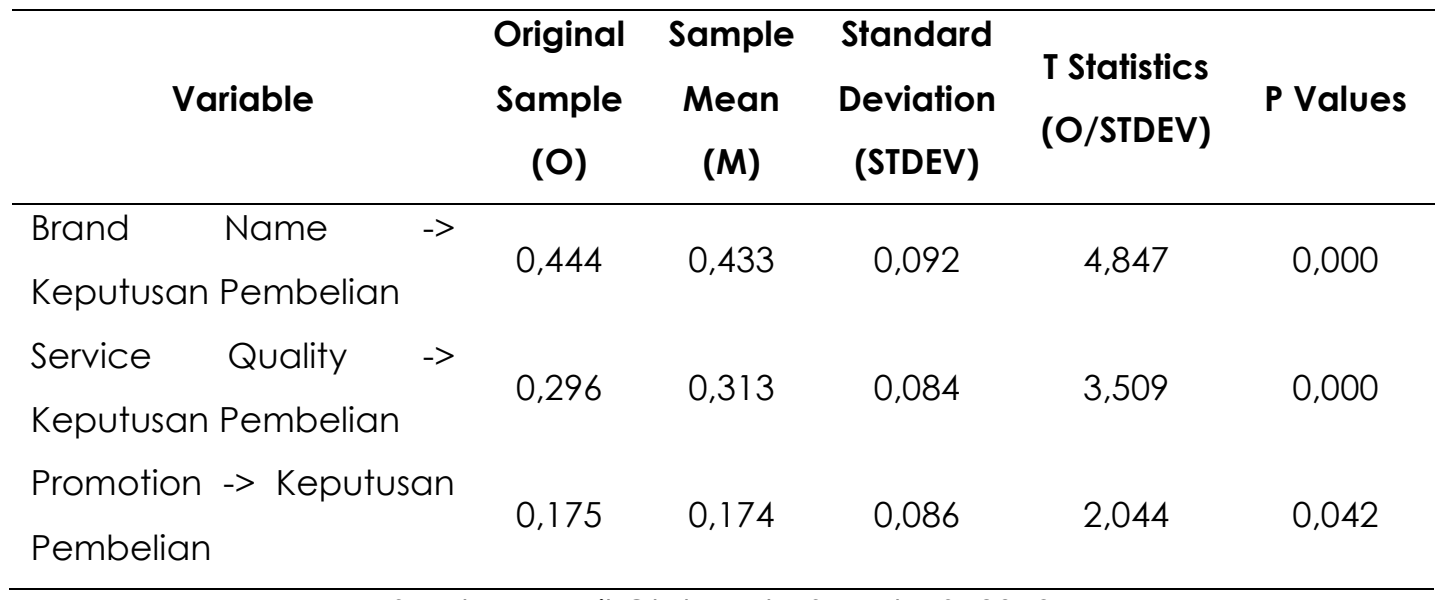

Sumber: Hasil Olah Data SmartPLS, 2018 
Hasil dari olah data Path Coefficients adalah sebagai berikut:

$\mathrm{T}-1$ = Hipotesis pengujian variabel Xl (Brand Name) terhadap variabel Y (Keputusan

Pembelian Pelanggan)

$\mathrm{HO}=$ Tidak ada pengaruh positif antara Brand Name terhadap Keputusan Pembelian Pelanggan.

$\mathrm{Ha}=$ Terdapat pengaruh positif antara Brand Name terhadap Keputusan Pembelian Pelanggan.

\section{Dasar Pengambilan Keputusan}

Tstatistik < Tvalue, maka HO tidak ditolak (didukung), Ha ditolak.

Tstatistik > Tvalue, maka Ha tidak ditolak (didukung), HO ditolak.

\section{Keputusan}

Tstatistik : : 4,847

Tralue $\quad: 1,84$

\section{Hasil}

Terdapat pengaruh positif antara Brand Name terhadap keputusan pembelian pelanggan sehingga $\mathrm{HO}$ ditolak.

$\mathrm{T}-2$ = Hipotesis pengujian variabel X2 (Service Quality) terhadap variabel Y (Keputusan Pembelian Pelanggan)

HO = Tidak ada pengaruh positif antara Service Quality terhadap Keputusan Pembelian Pelanggan.

$\mathrm{Ha}=$ Terdapat pengaruh positif antara Service Quality terhadap Keputusan Pembelian Pelanggan.

\section{Dasar Pengambilan Keputusan}

Tstatistik < Tvalue, maka HO tidak ditolak (didukung), Ha ditolak.

Tstatistik > Tvalue, maka Ha tidak ditolak (didukung), HO ditolak.

\section{Keputusan}

Tstatistik : 3,509

Tralue $\quad: 1,84$

\section{Hasil}

Terdapat pengaruh positif antara Service Quality terhadap keputusan pembelian pelanggan sehingga $\mathrm{HO}$ ditolak. 


\section{Lidwina RA Sinaga}

\section{Natasya Intan Pramanda}

$\mathrm{T}-3$ = Hipotesis pengujian variabel $\mathrm{X} 3$ (Promotion) terhadap variabel $\mathrm{Y}$ (Keputusan Pembelian Pelanggan)

$\mathrm{HO}=$ Tidak ada pengaruh positif antara Promotion terhadap Keputusan Pembelian Pelanggan.

$\mathrm{Ha}=$ Terdapat pengaruh positif antara Promotion terhadap Keputusan Pembelian Pelanggan.

\section{Dasar Pengambilan Keputusan}

Tstatistik < Tvalue, maka HO tidak ditolak (didukung), Ha ditolak.

Tstatistik > Tvalue, maka Ha tidak ditolak (didukung), HO ditolak.

\section{Keputusan}

Tstatistik : 2,044

Tralue $\quad: 1,84$

\section{Hasil}

Terdapat pengaruh positif antara Promotion terhadap keputusan pembelian pelanggan sehingga $\mathrm{HO}$ ditolak.

\section{Implikasi Hasil Penelitian}

\section{Pengaruh Brand Name terhadap Keputusan Pembelian Pelanggan}

Berdasarkan hasil pengujian hipotesis, Brand Name memiliki pengaruh positif terhadap Keputusan Pembelian pelanggan. Hal ini membuktikan bahwa keputusan pembelian yang ditentukan oleh pelanggan dipengaruhi oleh merek suatu produk. Konsumen akan memperhatikan merek yang dapat memberikan solusi atas permasalahan yang dialami setiap orang dan dalam hal ini adalah kebutuhan konsumen dalam membeli peralatan sehari-hari. Semakin suatu brand dikenal secara luas, mudah diingat oleh masyarakat, memiliki daya tarik dan memiliki perbedaan dengan kompetitor lainnya akan membuat pelanggan memilih brand tersebut. Selain itu reputasi dan informasi yang jelas dari suatu brand juga akan mempengaruhi pelanggan dalam memutuskan untuk membeli produk maupun jasa yang ditawarkan oleh perusahaan. Variabel brand name memiliki nilai uji FSquare terbesar diantara variabel yang diuji dalam penelitian ini yang menandakan bahwa terdapat pengaruh medium antara brand name terhadap keputusan pembelian pelanggan.

Dari hasil kuesioner yang disebarkan terkait brand name, masyarakat khususnya pengunjung Miniso Tunjungan Plaza Surabaya sudah mengetahui bahwa brand Miniso memiliki reputasi 
baik dan terpercaya. Rata-rata jawaban responden yang tidak setuju dan sangat tidak setuju berada di bawah sepuluh persen dari keseluruhan pernyataan mengenai variabel Brand Name. Oleh karena itu Miniso dapat meningkatkan brand name dengan cara menambahkan fitur produk dengan menciptakan merek melalui pertimbangan yang baik sebagai dasar diferensiasi produk terkait nama merek barunya melalui segmentasi dan positioning yang tepat seperti yang sudah dilakukan Miniso sebelumnya melalui variasi produk. Selain itu Miniso juga dapat membangun relasi yang kuat kepada pelanggan serta mencari tahu alasan dalam memilih produk tersebut melalui pengadaan event atau acara sebagai bentuk kepedulian perusahaan terhadap pengunjung yang dapat memberikan evaluasi sehingga perusahaan dapat mendengar langsung hal-hal yang diinginkan konsumen sehingga dapat meningkatkan keputusan pembelian pelanggan.

Brand Name

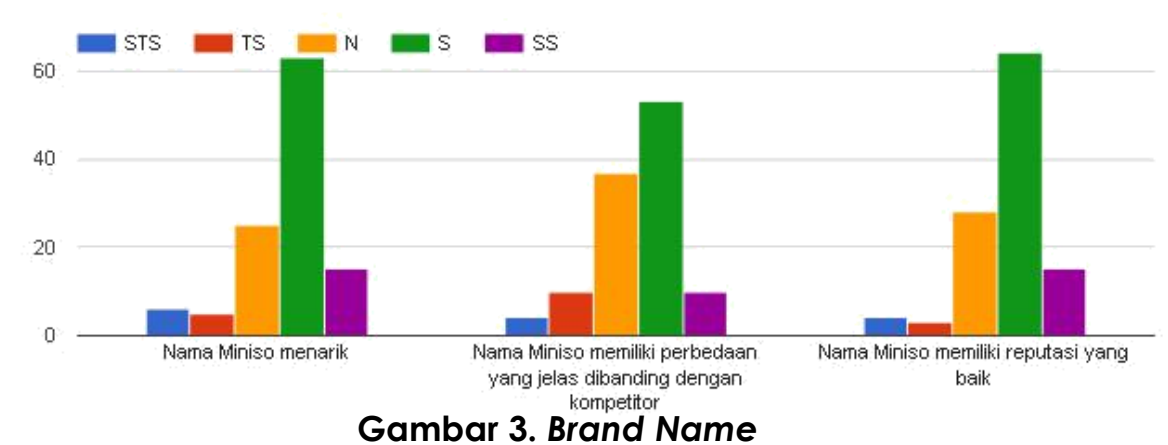

Sumber: Peneliti, 2018

\section{Pengaruh Service Quality terhadap Keputusan Pembelian Pelanggan}

Berdasarkan hasil pengujian hipotesis, service quality memiliki pengaruh positif terhadap keputusan pembelian pelanggan. Hal ini membuktikan bahwa kualitas jasa memiliki dampak atau berpengaruh terhadap perilaku membeli pelanggan. Semakin baik servis yang diberikan oleh perusahaan terhadap konsumen maka akan meningkatkan kemungkinan konsumen untuk memutuskan membeli produk maupun jasa yang dijual oleh perusahaan. Dimensi dalam kualitas jasa yang menjadi acuan adalah bukti yang dapat dirasakan dan terlihat seperti fasilitas, perlengkapan, dan pegawai (tangible). Selain itu, kualitas jasa juga dilihat dari kehandalan (reliability), daya tanggap (responsiveness), adanya jaminan yang dapat membuat pelanggan lebih percaya (assurance), dan empati yang diberikan dalam melakukan komunikasi (empathy). Variabel service quality memiliki nilai uji F-Square terendah diantara variabel yang diuji dalam penelitian ini yang menandakan bahwa terdapat pengaruh sangat kecil antara service quality terhadap keputusan pembelian pelanggan. 


\section{Lidwina RA Sinaga}

\section{Natasya Intan Pramanda}

Berdasarkan hasil kuesioner yang disebarkan terkait service quality, Miniso perlu meningkatkan kualitas pelayanan jasa kepada konsumen terutama pada area daya tanggap (responsiveness) dalam menyelesaikan persoalan dan keluhan yang dialami oleh konsumen ketika melakukan pembelian. Hal ini dikarenakan masih terdapat jawaban tidak setuju dan sangat tidak setuju atas pernyataan staf Miniso dalam menanggapi dan menangani keluhan konsumen dengan cepat dan tepat. Kemudian berdasarkan hasil kuesioner poin variasi produk, terdapat hampir $22 \%$ sejumlah 25 responden berpendapat bahwa produk Miniso sangat bervariasi. Maka diharapkan Miniso dapat secara berkala menambah variasi produk sehingga hal ini akan menarik konsumen untuk membeli produk di Miniso khusunya Tunjungan Plaza Surabaya. Pada poin pertanyaan berkaitan dengan sikap staf dalam image kualitas produk, lebih dari 50\% responden berpendapat bahwa sikap staff memberikan keyakinan kepada konsumen mengenai kualitas yang diberikan. Oleh karena itu Miniso perlu meningkatkan kualitas pelayanan jasa yang mereka berikan kepada konsumen dengan cara melakukan pelatihan kepada para staf dalam melayani konsumen dan menetapkan standar perilaku yang baik dalam menanggapi dan menangani masalah yang ada di lapangan. Miniso diharapkan dapat meningkatkan keputusan pembelian pelanggan dengan adanya respon dari pihak Miniso serta kualitas pelayanan yang baik.

\section{Service Quality}

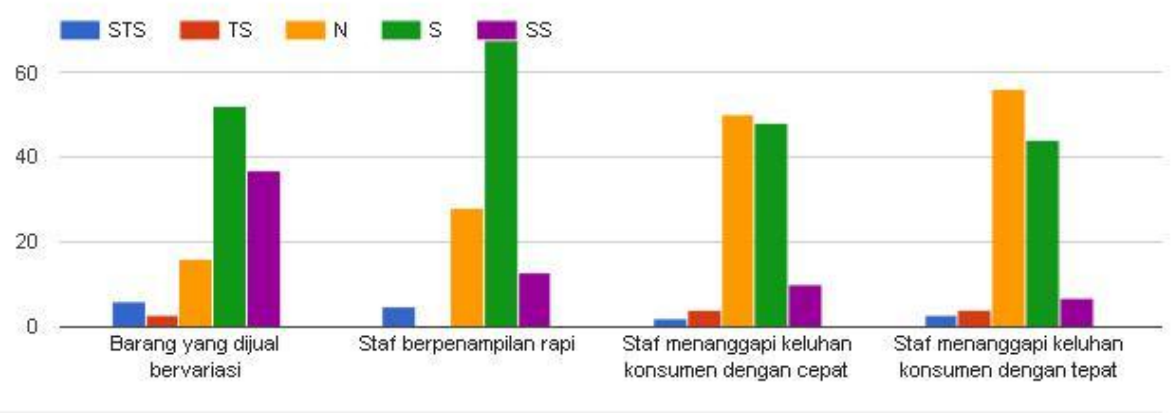

Gambar 4a. Service Quality

Sumber: Peneliti, 2018 


\section{Service Quality}

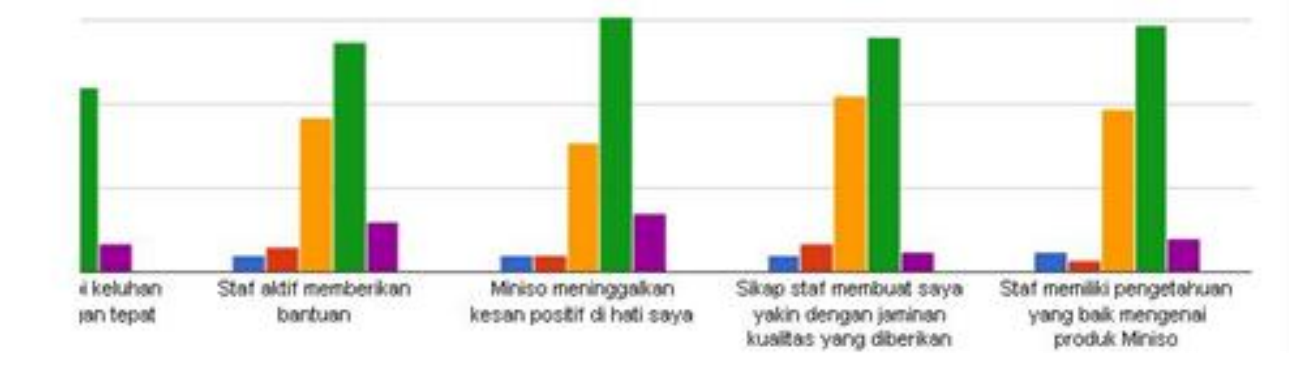

Gambar 4b. Service Quality

Sumber: Peneliti, 2018

\section{Pengaruh Promotion terhadap Keputusan Pembelian Pelanggan}

Berdasarkan hasil pengujian hipotesis, promotion memiliki pengaruh positif terhadap keputusan pembelian pelanggan. Hal ini membuktikan bahwa perilaku pengambilan keputusan untuk membeli oleh pelanggan dipengaruhi oleh promosi yang dilakukan oleh perusahaan. Semakin sering perusahaan melakukan aktivitas promosi ataupun komunikasi untuk mempengaruhi pelanggan dalam membeli produk atau jasa yang ditawarkan oleh perusahaan maka akan meningkatkan keputusan pembelian pelanggan. Promosi dapat dilakukan dengan berbagai cara dan sangat penting adanya sosialisasi produk dan jasa kepada masyarakat yang dapat menarik perhatian dan juga mengingatkan kembali kepada masyarakat atas suatu brand hingga mempengaruhi tingkat retensi pelanggan. Variabel promotion memiliki nilai uji F-Square terendah di antara variabel yang diuji dalam penelitian ini yang menandakan bahwa terdapat pengaruh promosi namun tidak sebesar brand name dan service quality terhadap keputusan pembelian pelanggan.

Berdasarkan hasil kuesioner yang disebarkan terkait promotion, Miniso belum banyak melakukan aktivitas promosi dimana $52 \%$ responden menyatakan belum setuju bahwa Miniso melakukan kegiatan promosi melalui diskon, begitu dengan publikasi yang dilakukan. Selain hal tersebut, $68.4 \%$ responden menyatakan tidak setuju dan tidak mengetahui program keanggotaan dilakukan oleh Miniso. Hal ini merupakan peluang yang bagus untuk Miniso membuat program sistem keanggotaan sehingga dapat digunakan oleh konsumen dalam melakukan pengumpulan poin dan melakukan penukaran hadiah reward atas poin yang dikumpulkan yang dapat meningkatkan keputusan pembelian serta tingkat retensi pelanggan. Lebih dari 50\% sejumlah 64 responden menyatakan setuju atas pernyataan promosi akan mempengaruhi tingkat retensi pengunjung Miniso, oleh karena itu Miniso perlu merencanakan kegiatan promosi oleh bagian pemasaran sehingga pihak Miniso dapat menarik perhatian konsumen sehingga meningkatkan keputusan pembelian. 


\section{Lidwina RA Sinaga}

\section{Natasya Intan Pramanda}

Berdasarkan nilai R-Square ketiga, variabel independen memiliki pengaruh yang moderat sebesar $66.5 \%$ terhadap keputusan pembelian pelanggan. Brand name yang semakin dikenal masyarakat, service quality atau pelayanan kualitas jasa yang memuaskan pengunjung serta aktivitas promosi dilakukan secara gencar, dapat meningkatkan keputusan pembelian pelanggan pada Miniso Tunjungan Plaza Surabaya. Terdapat $33.5 \%$ variabel independen lain di luar dari penelitian ini yang memiliki pengaruh terhadap keputusan pembelian pelanggan. Variabel independen di luar penelitian ini dapat berupa bagian dari marketing mix $4 P$ lainnya seperti product, price serta place. Selain itu terdapat pula variabel independen lain yang berupa kepuasan pelanggan (customer satisfaction), persepsi pelanggan (perceived quality), kesadaran merek (brand awareness), kepercayaan terhadap suatu merek (brand trust) dan loyalitas konsumen terhadap suatu brand (brand loyalty) yang memiliki dampak terhadap keputusan pembelian pelanggan.

\section{Promotion}

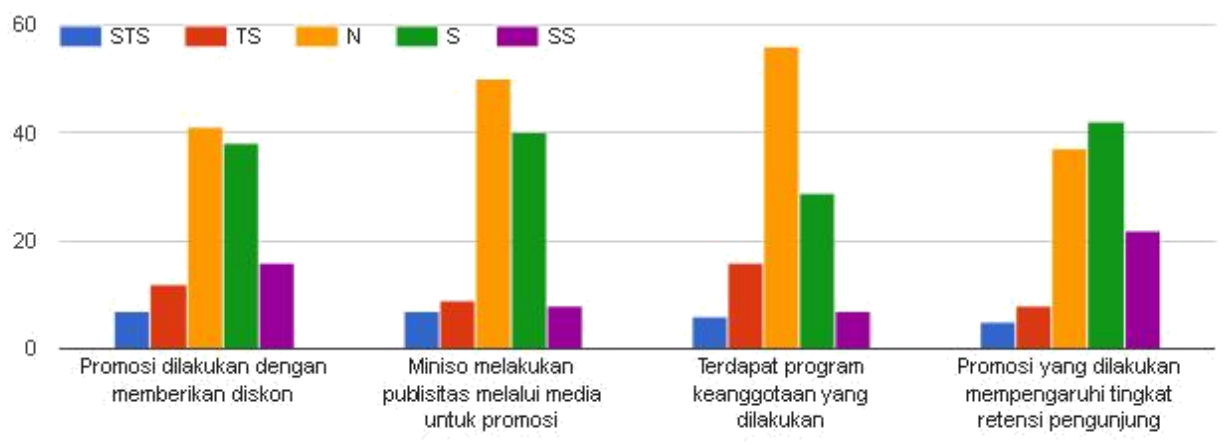

Gambar 5. Promotion

Sumber: Peneliti, 2018

\section{SIMPULAN}

Berdasarkan hasil analisis pengaruh brand name, service quality dan promotion terhadap keputusan pembelian pelanggan pada Miniso Tunjungan Plaza Surabaya pada periode April sampai dengan Mei 2018, dapat disimpulkan beberapa hal berikut:

1. Brand Name (X1) memiliki pengaruh positif terhadap Keputusan Pembelian Pelanggan (Y). Dengan demikian, meningkat atau menurunnya keputusan pembelian pelanggan dapat dijelaskan secara langsung oleh brand name.

Berdasarkan hasil dari penelitian ini dapat disimpulkan bahwa "Pengaruh Brand Name terhadap Keputusan Pembelian Pelanggan" atau Hipotesis 1 dinyatakan didukung.

2. Service Quality (X2) memiliki pengaruh positif terhadap Keputusan Pembelian Pelanggan (Y). Dengan demikian, meningkat atau menurunnya keputusan pembelian pelanggan dapat dijelaskan secara langsung oleh service quality. 
Berdasarkan hasil dari penelitian ini dapat disimpulkan bahwa "Pengaruh Service Quality terhadap Keputusan Pembelian Pelanggan" atau Hipotesis 2 dinyatakan didukung.

3. Promotion (X3) memiliki pengaruh positif terhadap Keputusan Pembelian Pelanggan (Y). Dengan demikian, meningkat atau menurunnya keputusan pembelian pelanggan dapat dijelaskan secara langsung oleh promotion.

Berdasarkan hasil dari penelitian ini dapat disimpulkan bahwa "Pengaruh Promotion terhadap Keputusan Pembelian Pelanggan" atau Hipotesis 3 dinyatakan didukung. 
Lidwina RA Sinaga

Natasya Intan Pramanda

\section{DAFTAR PUSTAKA}

Belch, G. E. dan Belch, M. A. 2015. Advertising and Promotion: An Integrated Marketing Communications Perspective (10th Global Edition). New York: McGrawHill Education.

Caroline. 2011. Pengaruh Brand Name, Store Name Dan Price Terhadap Perceived Value Untuk Memunculkan Purchased Intention. Tesis. Jakarta: Pascasarjana Universitas Pelita Harapan Jakarta.

Hair, J. F., Black, W. C., Babin, B. J., dan Anderson, E. 2013. Multivariate Data Analysis (7th Edition). New York: Pearson.

Hair, J. F., Hult, G. T. M., Ringle, C. M. dan Sarstedt, M. 2014. A Primer On Partial Least Squares Structural Equation Modeling (PLS-SEM). United Kingdom: Sage Publications, Inc.

Kotler, P. dan Armstrong, G. 2014. Principles of Marketing (15th Global Edition). England: Pearson Education.

Kary Schiffman, L. G. dan Kanuk, L. L. 2010. Consumer Behavior (10th Edition). New York: Pearson Education.

Sekaran, U. dan Bougie, R. 2013. Research Methods for Business (6th Edition). United Kingdom: Wiley.

Tjiptono, F. dan Chandra, G. 2011. Service, Quality and Satisfaction (3rd Edition). Yogyakarta: Andi. 